\title{
Kaitan Nilai Eigen Terbesar Matrik Antiadjacency dengan Operasi Maksimum dari Graf Lintasan Lengkap Berarah dan Graf Bipartit Lengkap Berarah, Graf Lintasan Lengkap Berarah dan Graf Lingkaran Berarah Asiklik
}

\author{
Rostika Listyaningrum ${ }^{1}$, Kiki Ariyanti Sugeng ${ }^{2}$, Nora Hariadi ${ }^{3}$ \\ ${ }^{1}$ Program Studi Teknik Informatika Politeknik Negeri Cilacap, \\ ${ }^{2,3}$ Departemen Matematika FMIPA Universitas Indonesia \\ ${ }^{1}$ nadhifa007@gmail.com, ${ }^{2}$ kiki@sci.ui.ac.id, ${ }^{3}$ nora.hariadi@sci.ui.ac.id
}

\begin{abstract}
Abstrak
Salah satu cara merepresentasikan graf ke dalam matriks adalah dengan menggunakan matriks antiadjacency. Misalkan $G$ adalah suatu graf berarah asiklik dengan $V(G)=\left\{v_{1}, v_{2}, \ldots, v_{n}\right\}$. Matriks adjacency dari graf berarah $G$ adalah matriks $A=\left[a_{i j}\right]$ yang berukuran $n \times n$ yang didefinisikan dengan $a_{i j}=1$, untuk $i \neq j$ jika terdapat busur berarah dari $v_{i}$ ke $v_{j}$ dan $a_{i j}=0$ untuk selainnya. Matriks $B=J-A$ disebut sebagai matriks antiadjacency dari graf berarah $G$ dengan $J$ adalah matriks yang berukuran $n \times n$ dengan semua entrinya adalah 1 . Pada jurnal ini dibahas kaitan antara nilai eigen terbesar matriks antiadjacency dengan operasi maksimum dari graf lintasan lengkap berarah dan graf bipartit lengkap berarah, graf lintasan lengkap berarah dan graf lingkaran berarah asiklik.

Kata kunci: graf berarah asiklik, graf bipartit lengkap berarah asiklik, graf lintasan lengkap berarah asiklik, graf lingkaran berarah asiklik, matriks antiadjacency, nilai eigen terbesar, operasi maksimum.
\end{abstract}

\begin{abstract}
One of the way to represent a graph in a matrix is by using an antiadjacency matrix. Let $G$ be a directed acyclic graph with $V(G)=$ $\left\{v_{1}, v_{2}, \ldots, v_{n}\right\}$. The adjacency matrix of directed graph $G$ is a matrix $A=\left[a_{i j}\right]$ of order $n \times n$, such that if there is an arc from $v_{i}$ to $v_{j}$ then $a_{i j}=1$, otherwise $a_{i j}=0$. The matrix $B=J-A$ will be called antiadjacency matrix of directed graph $G$ with $J$ is a matrix of order $n \times n$ with all entries are 1 . This journal discuss the relation between the largest eigen value of antiadjacency matrix with maximum operation matrix of complete pathdirected acyclic graph and complete bipartite directed acyclic graph, complete pathdirected acyclic graph and acyclic cycle directed graph.

Keywords :directed acyclic graph, complete bipartite directed acyclic graph, complete path directed acyclic graph, acyclic cycle directed graph, antiadjacency matrix, the largest eigen value, maximum operation..
\end{abstract}

2000 Mathematics Subject Classification: $97 \mathrm{~K} 20$ Received: 2017-07-13, accepted: 2018-04-04. 


\section{Pendahuluan}

Graf yang dibahas dalam makalah ini adalah graf berarah sederhana asiklik. Suatu graf berarah $G$ adalah pasangan terurut dari dua himpunan $V(G)$ dan $E(G)$. Himpunan $V(G)$ adalah himpunan simpul berhingga yang tak kosong dan himpunan $E(G)$ adalah himpunan busur berarah yang merupakan kumpulan dari pasangan terurut anggota dari $V(G)$. Graf berarah $G$ disebut graf berarah sederhana jika $G$ tidak memuat loop dan busur berarah yang sejajar [4]. Sebelum diberikan kaitan nilai eigen terbesar matrik antiadjacency dengan operasi maksimum dari graf lintasan lengkap berarah dan graf bipartit lengkap berarah, graf lintasan lengkap berarah dan graf lingkaran berarah asiklik, berikut diberikan beberapa definisi yang diperlukan untuk pembahasan selanjutnya.

Definisi 1.1. [2] Matriks adjacency dari graf berarah $G$ adalah matriks $A=\left[a_{i j}\right]$ berukuran $n \times n$ yang didefinisikan sebagai berikut :

$$
a_{i j}=\left\{\begin{array}{l}
1, \text { untuk } i \neq j \text { jika terdapat busur berarah dari } v_{i} \text { ke } v_{j} \\
0, \text { untuk selainnya. }
\end{array}\right.
$$

Matriks antiadjacency dari graf berarah $G$ adalah matriks $B=J-A$, dengan $J$ adalah matriks berukuran $n \times n$ yang semua entrinya adalah 1 .

Definisi 1.2. [6] Misalkan $A$ dan $B$ adalah matriks, jumlahan dari max matriks dinotasikan dengan $\oplus$ dan didefinisikan sebagai $[A \oplus B]_{i, j}=a_{i j} \oplus b_{i j}=\max \left(a_{i j}, b_{i j}\right)$ di mana $a_{i j}$ dan $b_{i j}$ secara berturut-turut adalah entri baris ke $i$ dan kolom ke $j$ dari matriks $A$ dan $B$.

Definisi 1.3. [3] Nilai eigen matriks $A$ dari suatu graf $G$ merupakan akar-akar $\lambda_{1}, \lambda_{2}, \ldots, \lambda_{n}$ yang didapatkan dari persamaan karakteristik $p(A)=\operatorname{det}(\lambda I-A)=0$.

Definisi 1.4. [3] Misalkan matriks adjacency A mempunyai $n$ nilai eigen yang berbeda yaitu $\lambda_{1}>\lambda_{2}>\ldots>\lambda_{s}$ dengan multiplisitas aljabar masing-masing adalah $m\left(\lambda_{1}\right), m\left(\lambda_{2}\right), \ldots, m\left(\lambda_{s}\right)$. Maka spektrum matriks $A$ dari suatu graf $G$ adalah :

$$
\operatorname{Spec}(A(G))=\left(\begin{array}{cccc}
\lambda_{1} & \lambda_{2} & \ldots & \lambda_{s} \\
m\left(\lambda_{1}\right) & m\left(\lambda_{2}\right) & \ldots & m\left(\lambda_{s}\right)
\end{array}\right) .
$$

Definisi 1.5. [2] Misal $G$ adalah graf dengan $n$ simpul dan dengan nilai eigen $\lambda_{1} \geq \cdots \geq \lambda_{n}$. Nilai eigen terbesar dan nilai eigen terkecil pada graf $G$ berturut-turut dinyatakan dengan $\lambda_{1}(G)$ dan $\lambda_{n}(G)$.

Teorema 1.6. [8] Jika $\lambda^{n}+c_{1} \lambda^{n-1}+c_{2} \lambda^{n-2}+c_{3} \lambda^{n-3}+\cdots+c_{n}=0$ adalah persamaan karakeristik dari matriks $A_{n \times n}$ maka $c_{i}=(-1)^{i} \sum_{j=1}^{w}\left|A_{i}^{(j)}\right|$ dengan $i=1,2, \ldots, n$ di mana $\left|A_{i}^{(j)}\right|$ adalah minor utama yang berukuran $i \times i$ dari matriks $A$ dan $j=1,2,3, \ldots, w$ dengan $w$ adalah banyaknya minor utama yang berukuran $i \times i$ dari matriks $A$.

Teorema 1.7. [5] Misalkan $G$ adalah suatu graf berarah yang asiklik dengan $V(G)=\left\{v_{1}, v_{2},, v_{n}\right\}$. Misalkan $B$ adalah matriks antiadjacency dari graf berarah $G$ dengan polinomial karakteristiknya adalah $p(B(G))=\operatorname{det}(\lambda I-B(G))=\lambda^{n}+b_{1} \lambda^{n-1}+b_{2} \lambda^{n-2}+b_{3} \lambda^{n-3}+\cdots+b_{n}$. Maka $\left|b_{i}\right|, i=1,2,3, \ldots, n$ menyatakan banyaknya lintasan berarah dari graf berarah $G$ dengan panjang $i-1$.

Definisi 1.8. [1] Graf bipartit lengkap berarah $\vec{K}_{r, s}$ untuk $r, s \geq 1$ adalah graf berarah sederhana yang himpunan simpulnya dipartisi menjadi dua himpunan $X$ dan $Y$ yang saling lepas, sehingga setiap busur berarah mempunyai awal di $X$ dan akhir di $Y . X=\left\{v_{1}, \ldots, v_{r}\right\}$ dan $Y=\left\{v_{r+1}, \ldots, v_{r+s}\right\} . \quad X$ disebut himpunan pemancar dan $Y$ disebut himpunan penerima. Graf bipartit lengkap berarah $\vec{K}_{r, s}$ memiliki jumlah simpul $n=r+s$. Pada Gambar 1 diberikan ilustrasi dari graf bipartit lengkap berarah $\vec{K}_{r, s}$.

Lemma 1.9. [5] Spektrum matriks antiadjacency dari graf bipartit lengkap berarah $\vec{K}_{r, s}$ dengan $r, s \geq 1$ adalah $\operatorname{Spec}\left(B\left(\vec{K}_{r, s}\right)\right)=\left(\begin{array}{ccc}r & s & 0 \\ 1 & 1 & r+s-2)\end{array}\right)$. 


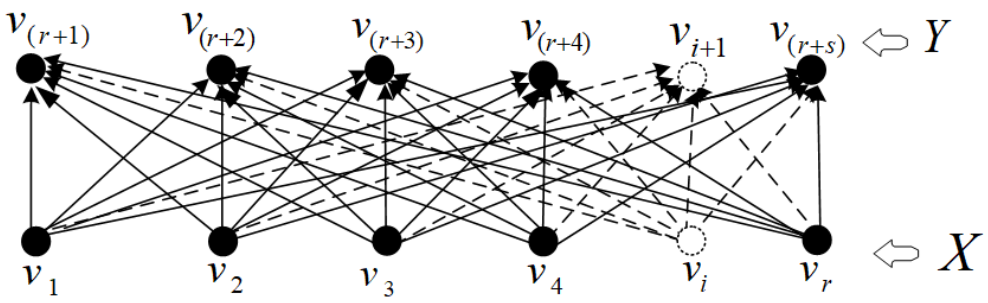

Gambar 1. Ilustrasi graf bipartit lengkap berarah graf $\vec{K}_{r, s}$.

Definisi 1.10. [4] Graf lintasan lengkap berarah $\overrightarrow{C P}_{n}$ dengan $n \geq 3$ adalah graf berarah sederhana yang mempunyai himpunan simpul $V=\left\{v_{1}, v_{2}, \ldots, v_{n}\right\}$ dan himpunan busur berarah $E=\left\{v_{i} v_{i+j} \mid i=1,2, \ldots, n-1, j=1,2, \ldots, n-i\right\}$. Gambar 2 di bawah ini adalah ilustrasi dari graf lintasan lengkap berarah $\overrightarrow{C P}_{n}$.

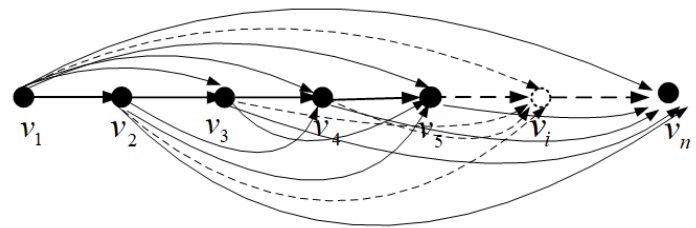

Gambar 2. Ilustrasi graf lintasan lengkap berarah $\overrightarrow{C P}_{n}$.

Lemma 1.11. [5] Spektrum matriks antiadjacency dari graf lintasan lengkap berarah $\overrightarrow{C P}_{n}$ dengan $n \geq 1$ adalah $\operatorname{Spec}\left(B\left(\overrightarrow{C P}_{n}\right)\right)=\frac{1}{n}$.

Definisi 1.12. [7] Jika himpunan simpul dari suatu graf $G$ dengan jumlah simpul $n \geq 3$ diberi label $v_{1}, v_{2}, \ldots, v_{n}$ sehingga busur dari graf $G$ adalah $v_{1} v_{2}, v_{2} v_{3}, \ldots, v_{n-1}, v_{n}, v_{n+1}$ maka graf $G$ disebut graf lingkaran. Graf lingkaran berarah adalah graf lingkaran yang setiap busurnya diberi arah tertentu. Graf lingkaran berarah asiklik $\underset{C_{n}}{\rightleftarrows}$ adalah graf lingkaran berarah yang tidak memiliki siklus berarah. Gambar 3 di bawah ini adalah contoh ilustrasi dari graf lingkaran berarah asiklik $\underset{C_{6}}{\rightleftarrows}$.

Definisi 1.13. [9] Suatu graf berarah $G$ disebut graf bipartit berarah $\vec{G}_{r, s}$ untuk $r, s \geq 1$ jika himpunan simpulnya dapat dipartisi menjadi dua himpunan $X$ dan $Y$, yang saling lepas sehingga terdapat busur berarah mempunyai awal di $X$ dan akhir di $Y$. Contoh pada Gambar 4 adalah graf bipartit berarah $\vec{G}_{3,4}$.

\section{Metode Penelitian}

Penelitian ini dilakukan melalui studi literatur dengan mempelajari makalah dan bukubuku yang berkaitan dengan topik penelitian. Selanjutnya hasil studi literatur tersebut digunakan sebagai landasan teori untuk mendapatkan kaitan antara nilai eigen terbesar matriks antiadjacency dengan operasi maksimum dari graf lintasan lengkap berarah dan graf bipartit lengkap berarah, graf lintasan lengkap berarah dan graf lingkaran berarah asiklik. 


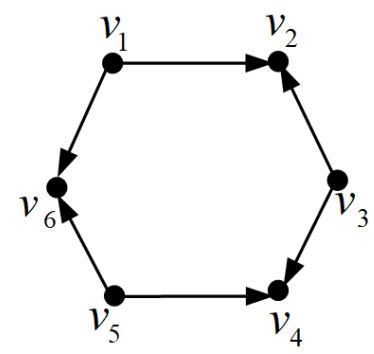

GAMBAR 3. Ilustrasi graf lingkaran berarah asiklik $\underset{C_{n}}{\rightleftarrows}$

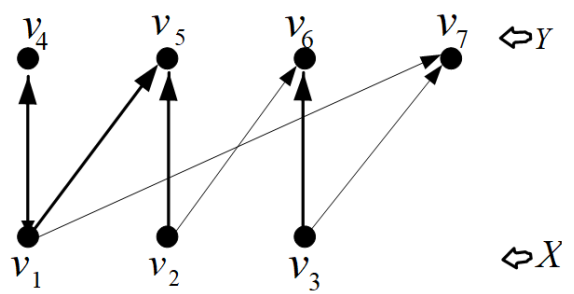

Gambar 4. Graf bipartit berarah $\vec{G}_{3,4}$.

\section{Hasil dan Pembahasan}

3.1. Kaitan operasi maksimum matriks antiadjacency dari dua buah graf berarah asiklik. Dalam Lemma 3.1 diberikan kaitan operasi maksimum matriks antiadjacency dari dua buah graf berarah asiklik. Perhatikan bahwa

$$
[B(G) \oplus B(H)]_{i, j}=g_{i j} \oplus h_{i j}=\max \left(g_{i j}, h_{i j}\right),
$$

di mana $B(G), B(H)$ adalah matriks antiadjacency dari graf $G$ dan $H$, dan entri baris ke i dan kolom ke j dari $B(G)$ dan $B(H)$ dinyatakan dengan $g_{i j}$ dan $h_{i j}$. Graf yang direpresentasikan oleh matriks antiadjacency $B(G) \oplus B(H)$ ditulis sebagai graf $G \oplus H$.

Lemma 3.1. Misalkan $G$ dan $H$ dua graf berarah asiklik pada himpunan simpul $\{1,2, \ldots, n\}$, dengan $V(G)=V(H)$ maka $G \oplus H=G \cap H$.

Bukti. Misalkan $D=G \oplus H$ adalah graf yang direpresentasikan oleh matriks antiadjacency $B(G) \oplus B(H)$, dengan $[B(G) \oplus B(H)]_{i, j}=g_{i j} \oplus h_{i j}=\max \left(g_{i j}, h_{i j}\right)$.

Karena $[B(G) \oplus B(H)]_{i, j}=\max \left(g_{i j}, h_{i j}\right)$,

maka $[B(G) \oplus B(H)]_{i, j}=0 \Longleftrightarrow g_{i j}=0$ dan $h_{i j}=0 \Longleftrightarrow$ Busur berarah $v_{i}, v_{j}$ ada di $G$ dan ada di $H$. Maka $E(D)=E(G \oplus H)=E(G) \cap E(H)$.

Selanjutnya karena $V(G)=V(H)$ maka $V(D)=V(G \oplus H)=V(G) \cap V(H)$.Jadi $G \oplus H=$ $G \cap H$.

3.2. Kaitan nilai eigen terbesar matriks antiadjacency dengan operasi maksimum dari graf lintasan lengkap berarah dan graf bipartit lengkap berarah. Dalam Teorema 3.2 diberikan kaitan nilai eigen terbesar matriks antiadjacency dengan operasi maksimum dari graf lintasan lengkap berarah $\overrightarrow{C P}_{n}$ dan graf bipartit lengkap berarah $\vec{K}_{r, s}$. Perhatikan bahwa nilai eigen terbesar graf yang direpresentasikan oleh matriks antiadjacency $\lambda_{1}(B(G))$ ditulis sebagai $\lambda_{1}(G)$.

Teorema 3.2. Misalkan $\overrightarrow{C P}_{n}$ adalah graf lintasan lengkap berarah dan $\vec{K}_{r, s}$ adalah graf bipartit lengkap berarah. Maka $\overrightarrow{C P}_{n} \oplus \vec{K}_{r, s}=\vec{K}_{r, s}$ dan $\lambda_{1}\left(\overrightarrow{C P}_{n} \oplus \vec{K}_{r, s}\right) \leq \lambda_{1}\left(\overrightarrow{C P}_{n}\right)+\lambda_{1}\left(\vec{K}_{r, s}\right)$. 
Bukti. Misalkan $V\left(\overrightarrow{C P}_{n}\right)$ adalah himpunan simpul dari $\overrightarrow{C P}_{n}$, maka $V\left(\overrightarrow{C P}_{n}\right)=\left\{v_{1}, v_{2}, \ldots, v_{n}\right\}$. Perhatikan bahwa simpul-simpul dari $\overrightarrow{C P}_{n}$ dan $\vec{K}_{r, s}$ harus sama jadi $n=r+s . \vec{K}_{r, s}$ adalah graf bipartit lengkap maka himpunan simpul dapat dipartisi menjadi $V$ dan $W$, dengan $V=$ $\left\{v_{1}, v_{2}, \ldots, v_{r}\right\}$ dan $W=\left\{v_{r+1}, v_{r+2}, \ldots, v_{n}\right\}$. Berdasarkan Lemma 3.1 maka $\overrightarrow{C P}_{n} \oplus \vec{K}_{r, s}=$ $\overrightarrow{C P}_{n} \cap \vec{K}_{r, s}$, sedangkan semua busur berarah $v_{i} v_{j}$ yang ada di $\vec{K}_{r, s}$ terletak di $\overrightarrow{C P}_{n}$, maka $\overrightarrow{C P}_{n} \oplus \vec{K}_{r, s}=\vec{K}_{r, s}$.

Jadi $\lambda_{1}\left(\overrightarrow{C P}_{n} \oplus \vec{K}_{r, s}\right)=\lambda_{1}\left(\vec{K}_{r, s}\right)$.

$\lambda_{1}\left(\vec{K}_{r, s}\right) \leq 1+\lambda_{1}\left(\vec{K}_{r, s}\right)=\lambda_{1}\left(\overrightarrow{C P}_{n}\right)+\lambda_{1}\left(\vec{K}_{r, s}\right)$ karena $\lambda_{1}\left(\overrightarrow{C P}_{n}\right)=1$, menurut Lemma 1.1. Maka terbukti $\lambda_{1}\left(\overrightarrow{C P}_{n} \oplus \vec{K}_{r, s}\right) \leq \lambda_{1}\left(\left(\overrightarrow{C P}_{n}\right)+\lambda_{1}\left(\vec{K}_{r, s}\right)\right.$.

3.3. Kaitan nilai eigen terbesar matriks antiadjacency dengan operasi maksimum dari graf lintasan lengkap berarah dan graf lingkaran berarah asiklik. Sebelum masuk ke Teorema 3.5 diberikan Teorema 3.3 yang membahas spektrum matriks antiadjacency dari graf bipartit berarah $\vec{G}_{r, s}$, dan teorema 3.4 yang membahas spektrum matriks antiadjacency dari graf lingkaran berarah asiklik $\underset{C_{n}}{\rightleftarrows}$

Teorema 3.3. Spektrum matriks antiadjacency dari graf bipartit berarah $\vec{G}_{r, s}$ dengan $r, s \geq 1$ $\operatorname{adalah}\left(\begin{array}{ccc}\frac{n+\sqrt{n^{2}-4 m}}{2} & \frac{n-\sqrt{n^{2}-4 m}}{2} & 0 \\ 1 & 1 & n-2\end{array}\right)$.

Perhatikan bahwa $n=r+s, n$ menyatakan jumlah simpul dan $m$ menyatakan banyaknya busur berarah.

Bukti. Misalkan $B\left(\vec{G}_{r, s}\right)$ adalah matriks antiadjacency dari graf bipartit berarah $\vec{G}_{r, s}$ dengan $r, s \geq 1$. Menurut Teorema 1.7 polinomial karakteristik matriks antiadjacency dari graf bipartit berarah $\vec{G}_{r, s}$ dengan $r, s \geq 1$ adalah $p\left(B\left(\vec{G}_{r, s}\right)=\lambda^{n}+b_{1} \lambda^{n-1}+b_{2} \lambda^{n-2}\right.$, karena $\vec{G}_{r, s}$ tidak mempunyai lintasan dengan panjang lebih dari satu.

Berdasarkan Teorema 1.6 diperoleh bahwa koefisien $\lambda^{n-i}$ adalah $b_{i}=(-1)^{i} \sum_{j=1}^{w}\left|B_{i}^{(j)}\right|$ dengan $i=1,2,3$ di mana $\left|B_{i}^{(j)}\right|$ adalah minor utama yang berukuran $i \times i$ dari matriks $B\left(\vec{K}_{r, s}\right)$ dan $j=1,2,3, \ldots, w$, dengan $w$ adalah banyaknya minor utama yang berukuran $i \times i$ dari matriks $B\left(\vec{K}_{r, s}\right)$. Selanjutnya berdasarkan Teorema 1.7 didapatkan bahwa koefisien $\left|b_{i}\right|$ menyatakan banyaknya lintasan berarah dari $B\left(\vec{K}_{r, s}\right)$ dengan panjang $i-1$.

Karena graf bipartit berarah $\vec{G}_{r, s}$ mempunyai simpul sebanyak $n=r+s$ dan mempunyai $m$ busur berarah, maka berdasarkan Teorema 1.6 dan Teorema 1.7 diperoleh bahwa $b_{1}=$ $-n, b_{2}=m$. Sehingga polinomial karakteristik matriks antiadjacency dari graf bipartit berarah $\vec{G}_{r, s}$ dengan $r, s \geq 1$ adalah $p\left(B\left(\vec{G}_{r, s}\right)\right)=\lambda^{n}-(n) \lambda^{n-1}+(m) \lambda^{n-2}$. Untuk $p\left(B\left(\vec{G}_{r, s}\right)\right)=0$ diperoleh $\lambda^{n}-(n) \lambda^{n-1}+(m) \lambda^{n-2}=0$ sehingga $\lambda^{n-2}\left(\lambda^{2}-n \lambda+m\right)=0$. Perhatikan bahwa $\lambda^{n-2}=0$, maka diperoleh $\lambda=0$ sebanyak $n-2$. Perhatikan bahwa $\lambda^{2}-n \lambda+m=0$, maka diperoleh $\lambda_{1}=\frac{n+s q r t n^{2}-4 m}{2}$ dan $\lambda_{1}=\frac{n-\sqrt{n^{2}-4 m}}{2}$. Jadi diperoleh nilai eigen dari $B\left(\vec{G}_{r, s}\right)$ adalah $\frac{n+\sqrt{n^{2}-4 m}}{2}, \frac{n-\sqrt{n^{2}-4 m}}{2}, 0$ dengan multiplisitasnya berturut-turut adalah 1,1 dan $n-2$. Maka spektrum matriks antiadjacency dari graf bipartit berarah $\vec{G}_{r, s}$ untuk $r, s \geq 1$ adalah $\left(\begin{array}{ccc}\frac{n+\sqrt{n^{2}-4 m}}{2} & \frac{n-\sqrt{n^{2}-4 m}}{2} & 0 \\ 1 & 1 & n-2\end{array}\right)$.

Teorema 3.4. Spektrum matriks antiadjacency dari graf graf lingkaran berarah asiklik $\underset{C_{n}}{\rightleftarrows}$, dengan $n \geq 4$, $n$ simpul genap dan mempunyai $n$ lintasan panjang satu adalah $\left(\begin{array}{ccc}\frac{n+\sqrt{n^{2}-4 m}}{2} & \frac{n-\sqrt{n^{2}-4 m}}{2} & 0 \\ 1 & 1 & n-2\end{array}\right), n$ simpul ganjil mempunyai $n$ lintasan panjang satu dan 1 lintasan panjang dua adalah $\left(\begin{array}{cccc}\frac{(n-1)+\sqrt{(1-n)^{2}-4}}{2} & 1 & \frac{(n-1)-\sqrt{(1-n)^{2}-4}}{2} & 0 \\ 1 & 1 & 1 & n-3\end{array}\right)$. 
Bukti. Pembuktian dibagi menjadi 2 kasus untuk n simpul genap dan n simpul ganjil.

(1) Kasus pertama : untuk $n$ simpul genap dan mempunyai $n$ lintasan panjang satu. Menggunakan Teorema 1.7 diperoleh bahwa polinomial karakteristik matriks antiadjacency dari graf lingkaran berarah asiklik $\underset{C_{n}}{\rightleftarrows}$, dengan $n \geq 4$ adalah $p\left(B\left(\stackrel{\rightleftarrows}{C_{n}}\right)\right)=\lambda^{n}+$ $b_{1} \lambda^{n-1}+b_{2} \lambda^{n-2}$, karena $\underset{C_{n}}{\rightleftarrows}$ tidak mempunyai lintasan dengan panjang lebih dari satu. Berdasarkan Teorema 1.6 diperoleh bahwa koefisien $\lambda^{n-i}$ adalah $b_{i}=(-1)^{i} \sum_{j=1}^{w}\left|B_{i}^{(j)}\right|$ dengan $i=1,2$, di mana $\left|B_{i}^{(j)}\right|$ adalah minor utama yang berukuran $i \times i$ dari matriks $B\left(\stackrel{\rightleftarrows}{C_{n}}\right)$ dan $j=1,2,3, \ldots, w$, dengan w adalah banyaknya minor utama yang berukuran $i \times i$ dari matriks $B\left(\stackrel{\rightleftarrows}{C_{n}}\right)$. Selanjutnya berdasarkan pembatasan kasus diketahui bahwa graf lingkaran berarah asiklik $\underset{C_{n}}{\rightleftarrows}$ dengan $n \geq 4, n$ simpul genap dan mempunyai $n$ lintasan dengan panjang satu. Lebih lanjut berdasarkan Teorema 1.7 didapatkan bahwa koefisien $\left|b_{i}\right|$ menyatakan banyaknya lintasan berarah dari $\underset{C_{n}}{\rightleftarrows}$ dengan panjang $i$ - 1. Maka berdasarkan pembatasan kasus, Teorema 1.6 dan Teorema 1.7 diperoleh bahwa $b_{1}=-n, b_{2}=n$. Sehingga polinomial karakteristik matriks antiadjacency dari graf lingkaran berarah asiklik $\underset{C_{n}}{\rightleftarrows}$ dengan $n \geq 4, n$ simpul genap dan mempunyai $n$ lintasan dengan panjang satu adalah $p\left(B\left(\underset{C_{n}}{\rightleftarrows}\right)\right)=\lambda^{n}-(n) \lambda^{n-1}+(n) \lambda^{n-2}$. maka untuk $p\left(B\left(\stackrel{\rightleftarrows}{C_{n}}\right)\right)=0$ didapatkan $\lambda^{n}-(n) \lambda^{n-1}+(n) \lambda^{n-2}=0$. sehingga $\lambda^{n-2}\left(\lambda^{2}-n \lambda+n\right)=0$. Perhatikan bahwa $\lambda^{n-2}=0$ diperoleh $\lambda=0$ sebanyak $n-2$.

Perhatikan bahwa $\left(\lambda^{2}-n \lambda+n\right)=0$.

Diperoleh $\lambda_{1}=\frac{n+\sqrt{n^{2}-4 n}}{2}$ dan $\lambda_{2}=\frac{n-\sqrt{n^{2}-4 n}}{2}, 0$ dengan multiplisitasnya berturutturut adalah 1,1 dan $n-2$. Maka spektrum dari $B\left(\stackrel{\rightleftarrows}{C_{n}}\right)$ untuk $n$ simpul genap dan mempunyai $n$ lintasan panjang satu adalah $\left(\begin{array}{ccc}\frac{n+\sqrt{n^{2}-4 n}}{2} & \frac{n-\sqrt{n^{2}-4 n}}{2} & 0 \\ 1 & n-2\end{array}\right)$.

(2) Kasus kedua : Untuk $\mathrm{n}$ simpul ganjil mempunyai $\mathrm{n}$ lintasan panjang satu dan 1 lintasan panjang dua. Menggunakan Teorema 1.7 diperoleh polinomial karakteristik matriks antiadjacency dari graf lingkaran berarah asiklik $\underset{C_{n}}{\rightleftarrows}$, dengan $n \geq 4$ adalah

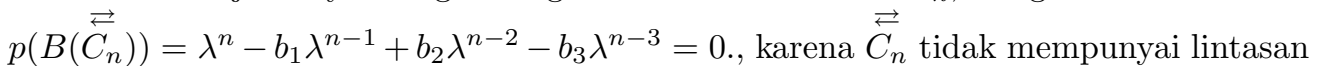
dengan panjang lebih dari dua. Berdasarkan Teorema 1.6 diperoleh bahwa koefisien $\lambda^{n-i}$ adalah $b_{i}=(-1)^{i} \sum_{j=1}^{w}\left|B_{i}^{(j)}\right|$ dengan $i=1,2,3$, di mana $\left|B_{i}^{(j)}\right|$ adalah minor utama yang berukuran $i \times i$ dari matriks $B\left(\stackrel{\rightleftarrows}{C_{n}}\right)$ dan $j=1,2,3, \ldots, w$, dengan $w$ adalah banyaknya minor utama yang berukuran $i \times i$ dari matriks $B\left(\stackrel{\rightleftarrows}{C_{n}}\right.$. Selanjutnya berdasarkan pembatasan kasus diketahui bahwa graf lingkaran berarah asiklik

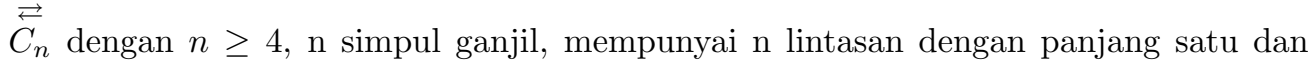
1 lintasan dengan panjang dua. Lebih lanjut berdasarkan Teorema 1.7 didapatkan bahwa koefisien $\left|b_{i}\right|$ menyatakan banyaknya lintasan berarah dari $\underset{C_{n}}{\rightleftarrows}$ dengan panjang $i-1$. Maka berdasarkan pembatasan kasus, Teorema 1.6 dan Teorema 1.7 diperoleh bahwa $b_{1}=-n, b_{2}=n$ dan $b_{3}=-1$. Sehingga polinomial karakteristik matriks antiadjacency dari graf lingkaran berarah asiklik $\underset{C_{n}}{\rightleftarrows}$ dengan $n \geq 4$, n simpul ganjil, mempunyai $n$ lintasan dengan panjang satu dan 1 lintasan dengan panjang dua adalah

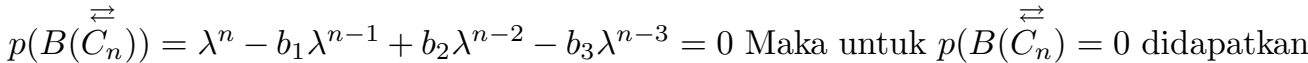
$\lambda^{n}-n \lambda^{n-1}+n \lambda^{n-2}-n^{n-3}=0$. $\lambda^{n-3}\left(\lambda^{3}-n \lambda^{2}+n \lambda-1\right)=0$. 
$\lambda^{n-3}(\lambda-1)\left(\lambda^{2}+(1-n) \lambda+1\right)=0$.

Perhatikan bahwa $\lambda^{n-3}=0$ diperoleh $\lambda=0$ sebanyak $n-3$.

Perhatikan bahwa $\lambda-1=0$ diperoleh $\lambda=1$ sebanyak 1 .

Perhatikan bahwa $\left.\lambda^{2}+(1-n) \lambda+1\right)=0$

Diperoleh $\lambda_{1}=\frac{(n-1)+\sqrt{(1-n)^{2}-4}}{\stackrel{2}{\rightleftarrows}}$ dan $\lambda_{2}=\frac{(n-1)-\sqrt{(1-n)^{2}-4}}{2}$.

(3) Jadi nilai eigen dari $B\left(\underset{C_{n}}{\rightleftarrows}\right)$ adalah $\frac{(n-1)+\sqrt{(1-n)^{2}-4}}{2}, \frac{(n-1)-\sqrt{(1-n)^{2}-4}}{2}, 0$ dan 1 dengan multiplisitasnya berturut-turut adalah $1,1, n-3$, dan 1 . Maka spektrum dari $B(\stackrel{\rightleftarrows}{\rightleftarrows})$ untuk $n$ simpul ganjil mempunyai $n$ lintasan panjang satu dan 1 lintasan panjang dua adalah $\left(\begin{array}{cccc}\frac{(n-1)+\sqrt{(1-n)^{2}-4}}{2} & 1 & \frac{(n-1)-\sqrt{(1-n)^{2}-4}}{2} & 0 \\ 1 & 1 & 1 & n-3\end{array}\right)$.

Teorema 3.5 membahas tentang kaitan nilai eigen terbesar matriks antiadjacency dan operasi maksimum dari graf lintasan lengkap berarah $\overrightarrow{C P}_{n}$ dan graf lingkaran berarah asiklik $\underset{C_{n}}{\rightleftarrows}$. Perhatikan bahwa

$E\left(\overrightarrow{C P}_{n}\right)=\left\{v_{i} v_{i+j} \mid i=1,2, \ldots, n-1, j=1,2, \ldots, n-i\right\}$, dan $V\left(\overrightarrow{C P}_{n}\right)=\left\{v_{1}, v_{2}, \ldots, v_{n}\right\}$ dengan $n \geq 4$.

Graf lingkaran berarah asiklik $\underset{C_{n}}{\rightleftarrows}$ yang dibahas dalam hal ini hanya dibatasi untuk kasus :

(1) $n$ genap, $n \geq 4$ dan mempunyai $n$ lintasan dengan panjang satu

$E\left(\stackrel{\rightleftarrows}{C_{n}}\right)=\left\{\begin{array}{l}v_{i} v_{i+1}, \text { untuk } i \text { ganjil, } 1 \leq i \leq n-1 . \\ v_{i+1} v_{i}, \text { untuk } i \text { genap, } 2 \leq i \leq n-2 .\end{array}\right.$

(2) $n$ ganjil, $n \geq 4$ dan mempunyai $n$ lintasan dengan panjang satu serta mempunyai 1 lintasan dengan panjang dua

$E(\stackrel{\rightleftarrows}{\rightleftarrows})=\left\{\begin{array}{l}v_{i} v_{i+1}, \text { untuk } i \text { ganjil, } 1 \leq i \leq n-2 \\ v_{i} i v_{i-1}, \text { untuk } i \text { ganjil, } 1 \leq i \leq n .\end{array}\right.$

Catatan $v_{0}=v_{n}$.

Teorema 3.5. Misalkan $\overrightarrow{C P}_{n}$ dan $\underset{C_{n}}{\rightleftarrows}$ adalah graf lintasan lengkap berarah dan graf lingkaran berarah asiklik, maka $\overrightarrow{C P}_{n} \oplus \underset{C_{n}}{\rightleftarrows}$ adalah sebuah graf bipartit berarah (tidak lengkap) dan $\lambda_{1}\left(\overrightarrow{C P}_{n} \oplus\right.$

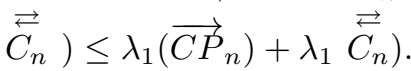

Bukti. Pembuktian dibagi menjadi 2 kasus untuk $n$ simpul genap dan $n$ simpul ganjil.

(1) Kasus pertama : Pembuktian untuk graf lingkaran berarah asiklik $\underset{C_{n}}{\rightleftarrows}$, dengan $n$ simpul genap dan mempunyai $n$ lintasan dengan panjang satu serta $\overrightarrow{C P}_{n}$ untuk $n$

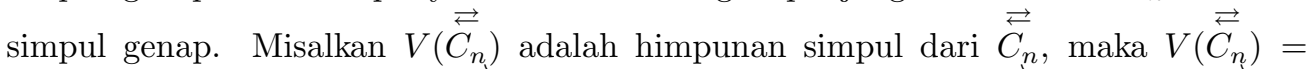
$\left\{v_{1}, v_{2}, \ldots, v_{n}\right\}$. Misalkan $V\left(\overrightarrow{C P}_{n}\right)$ adalah himpunan simpul dari $\overrightarrow{C P}_{n}$, maka $V\left(\overrightarrow{C P}_{n}\right)=$ $\left\{v_{1}, v_{2}, \ldots, v_{n}\right\}$. Perhatikan bahwa simpul-simpul dari $\overrightarrow{C P}_{n}$ dan $\underset{C_{n}}{\rightleftarrows}$ harus sama. Dari Lemma 3.1 diketahui $E\left(\overrightarrow{C P}_{n} \oplus \underset{C_{n}}{\rightleftarrows}\right)=E\left(\overrightarrow{C P}_{n}\right) \cap E\left(\underset{C_{n}}{\rightleftarrows}\right)=\left\{v_{i} v_{i+1} \mid\right.$ iganjil, $\left.1 \leq i \leq n-1\right\} \cup\left\{v_{1} v_{n}\right\}$

Pada Gambar 5 diberikan ilustrasi dari $\overrightarrow{C P}_{n} \oplus \underset{C_{n}}{\rightleftarrows}$ untuk n genap.

Misalkan $X=\left\{v_{i} \mid\right.$ iganjil, $\left.1 \leq i \leq n-1\right\}$ dan $Y=\left\{v_{i} \mid\right.$ igenap, $\left.2 \leq i \leq n\right\}$. Perhatikan bahwa $\overrightarrow{C P}_{n} \oplus \stackrel{C_{n}}{\rightleftarrows}$ merupakan graf bipartit dengan bipartisi $X \cup Y$. Maka menu-

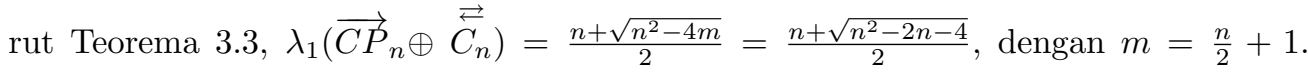


Menurut Lemma 1.11, diperoleh $\lambda_{1}\left(\overrightarrow{C P}_{n}\right)=1$, dan menurut Teorema 3.4, diperoleh $\lambda_{1}\left(\underset{C_{n}}{\rightleftarrows}\right)=\frac{n+\sqrt{n^{2}-4 n}}{2}$ untuk n genap.

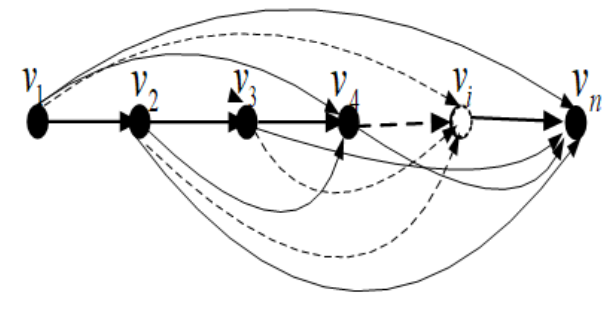

(a) $\overrightarrow{C P}_{n}$ untuk $n$ genap

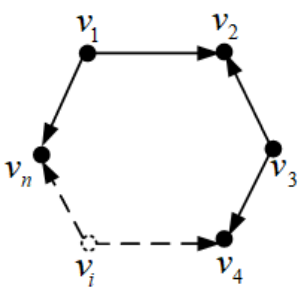

(b) $\overrightarrow{C_{n}}$ untuk $n$ genap

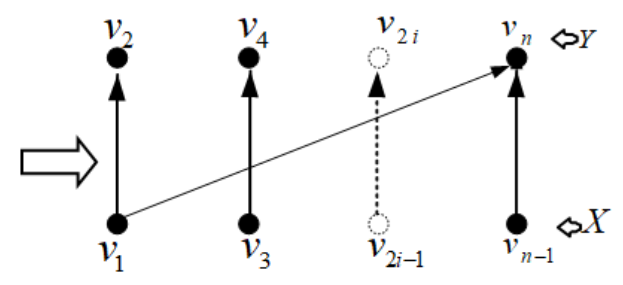

GAmBAR 5. Ilustrasi dari $\overrightarrow{C P}_{n}+\stackrel{\rightleftarrows}{\rightleftarrows}$ untuk n genap.

$$
\text { Akan dibuktikan } \frac{n+\sqrt{n^{2}-2 n-4}}{2} \leq 1+\frac{n+\sqrt{n^{2}-4 n}}{2},
$$

Pertidaksamaan (1) di atas setara dengan

$\Longleftrightarrow n+\sqrt{n^{2}-2 n-4} \leq 2+n+\sqrt{n^{2}-4 m}$

$\Longleftrightarrow \sqrt{n^{2}-2 n-4} \leq 2+\sqrt{n^{2}-4 m}$

$\Longleftrightarrow(n-4)^{2} \leq 4\left(n^{2}\right)-4 n$

Akan dibuktikan $(n-4)^{2} \leq 4\left(n^{2}-4 n\right)$ untuk $n \geq 4$,

$4\left(n^{2}-4 n\right)=4 n^{2}-16 n=n^{2}-8 n+16+3 n^{2}-8 n-16$.

Karena $3 n^{2}-8 n-16 \geq 0$ untuk $n \geq 4$, maka $4 n^{2}-16 n^{2} \geq n^{2}-8 n+16$ atau $4\left(n^{2}-4 n\right) \geq(n-4)^{2}$.

Pertidaksamaan (2) terbukti, sehingga pertidaksamaan (1) terbukti.

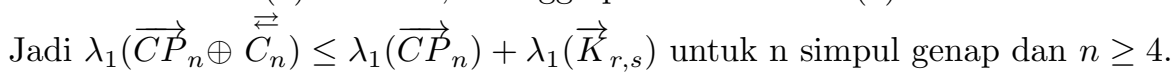

(2) Kasus kedua : Pembuktian untuk graf lingkaran berarah asiklik $\underset{C_{n}}{\rightleftarrows}$, dengan n simpul ganjil dan mempunyai n lintasan panjang satu, 1 lintasan panjang dua serta $\overrightarrow{C P}_{n}$ untuk n simpul ganjil. Misalkan $V\left(\underset{C_{n}}{\rightleftarrows}\right)$ adalah himpunan simpul dari $\underset{C_{n}}{\rightleftarrows}$, maka $V\left(\underset{C_{n}}{\rightleftarrows}\right)=\left\{v_{1}, v_{2}, \ldots, v_{n}\right\}$. Misalkan $V\left(\overrightarrow{C P}_{n}\right)$ adalah himpunan simpul dari $\overrightarrow{C P}_{n}$, maka $V\left(\overrightarrow{C P}_{n}\right)=\left\{v_{1}, v_{2}, \ldots, v_{n}\right\}$. Perhatikan bahwa simpul-simpul dari $\overrightarrow{C P}_{n}$ dan $\underset{C_{n}}{\rightleftarrows}$ harus sama. Dari Lemma 3.1 diketahui $E\left(\overrightarrow{C P}_{n} \oplus{\stackrel{\rightleftarrows}{C_{n}}}^{\rightleftarrows}=E\left(\overrightarrow{C P}_{n}\right) \cap E\left({\stackrel{C_{n}}{\rightleftarrows}}^{\rightleftarrows}=\left\{v_{i} v_{i+1} \mid i\right.\right.\right.$ ganjil, $\left.1 \leq i \leq n-2\right\} \cup\left\{v_{1} v_{n}\right\}$.

Pada Gambar 6 diberikan ilustrasi dari $\overrightarrow{C P}_{n} \oplus \underset{C_{n}}{\rightleftarrows}$ untuk n ganjil.

Misalkan $X=v_{i} \mid i$ ganjil, $1 \leq i \leq n-2$ dan $Y=v_{i}, v_{n} \mid i$ genap, $2 \leq i \leq n-1$. Per-

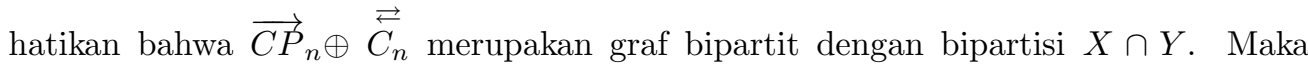

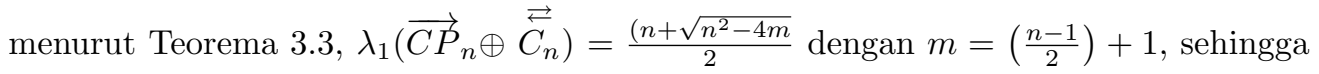




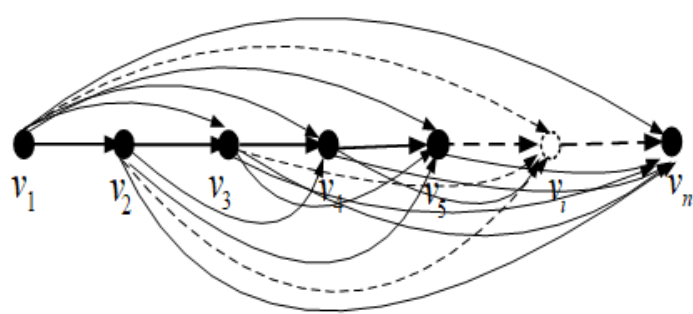

(a) $\overrightarrow{C P}_{n}$ untuk $n$ ganjil

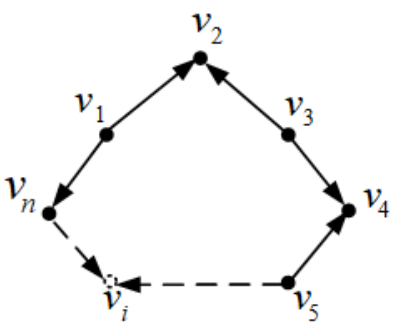

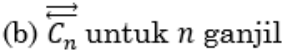

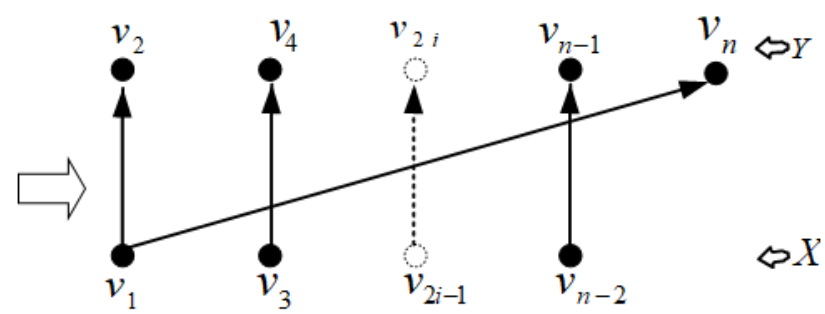

(c) $\overrightarrow{C P_{n}} \oplus \overrightarrow{C_{n}}$ untuk $n$ ganjil

Gambar 6. Ilustrasi dari $\overrightarrow{C P} n+\underset{C_{n}}{\rightleftarrows}$, untuk n ganjil

diperoleh $\lambda_{1}\left(\overrightarrow{C P}_{n} \oplus \underset{C_{n}}{\rightleftarrows}\right)=\frac{n+\sqrt{\left.n^{2}-4\left(\frac{n-1}{2}+1\right)\right)}}{2}=\frac{n+\sqrt{n^{2}-2 n-2}}{2}$. Menurut Lemma 1.11, $\lambda_{1}\left(\overrightarrow{C P}_{n}\right)=1$, dan menurut Teorema $3.4, \lambda_{1}\left(\vec{C}_{n}\right)=\frac{(n-1)+\sqrt{(1-n)^{2}-4}}{2}$ untuk $\mathrm{n}$ ganjil. Akan dibuktikan

$$
\frac{n+\sqrt{n^{2}-2 n-2}}{2} \leq 1+\frac{(n-1)+\sqrt{(1-n)^{2}-4}}{2}
$$

Pertidaksamaan (3) di atas setara dengan

$$
\begin{aligned}
& \Leftrightarrow \quad n+\sqrt{n^{2}-2 n-2} \leq 2+(n-1)+\sqrt{(1-n)^{2}-4} \\
& \Leftrightarrow \quad 0 \leq 4\left[(1-n)^{2}-4\right] .
\end{aligned}
$$

Akan dibuktikan $0 \leq 0 \leq 4\left[(1-n)^{2}-4\right]$ untuk $n \geq 4$.

$$
\begin{aligned}
4\left[(1-n)^{2}-4\right] & =4\left[n^{2}-2 n+1-4\right] \\
& =4\left[n^{2}-2 n-3\right] \\
& =4 n^{2}-8 n-12 .
\end{aligned}
$$

Karena $4 n^{2}-8 n-12>0$ untuk $n \geq 4$, maka $4\left[(1-n)^{2}-4\right] \geq 0$. Pertidaksamaan (4) terbukti, sehingga pertidaksamaan (3) terbukti. Jadi $\lambda_{1}\left(\overrightarrow{C P}_{n} \oplus \stackrel{\rightleftarrows}{C_{n}}\right) \leq \lambda_{1}\left(\overrightarrow{C P}_{n}\right)+$ $\lambda_{1}\left(\vec{C}_{n}\right)$ untuk n ganjil dan $n \geq 4$

\section{DAFtar Pustaka}

[1] Aigner, M., 1967, On The Linegraph of a directed Graph, Mathematische Zeitschrift.

[2] Bapat, R. B., 2010, Graphs and Matrices, Hindustan Book Agency, India.

[3] Biggs, N., 1993, Algebaraic Graph Theory (2nd ed), Cambridge Mathematical Library, New York.

[4] Chartran, G. and Lesniak, L., 1996, Graphs \& Digraphs (3rd ed), Chapman \& Hall/CRC, Florida. 
[5] Firmansah, F., 2014, Polinomial Karakteristik Matriks Antiadjacency dari Graf yang Asiklik. Tesis, Universitas Indonesia.

[6] Farlow, Kasie G. (2009). Max Plus Algebra. Thesis: Virginia Polytechnic Institute and State University.

[7] Chartran, G. and Zhang, P. (2005). Introduction to Graph Theory. New York : McGraw-Hill Education.

[8] Meyer, Carl D. (2000). Matrix Analysis and Applied Linier Algebra. New Jersey : SIAM.

[9] Reinhard Diestel, 2010 Graph Theory 4 ed, Graduate Texts in Mathematics, Springer, New York. 